\title{
Biomechanical Characteristics of Vertical Jumping of Preschool Children in China Based on Motion Capture and Simulation Modeling
}

\author{
Panchao Zhao *, Zhongqiu Ji, Ruixiang Wen, Jiahui Li, Xiao Liang and Guiping Jiang \\ College of P.E. and Sports, Beijing Normal University, Beijing 100875, China; jizhongqiu61@bnu.edu.cn (Z.J.); \\ 201731070010@mail.bnu.edu.cn (R.W.); 201821070031@mail.bnu.edu.cn (J.L.); \\ 201921070032@mail.bnu.edu.cn (X.L.); jiang_guiping0401@126.com (G.J.) \\ * Correspondence: 201931070012@mail.bnu.edu.cn or 18813001163@163.com
}

Citation: Zhao, P.; Ji, Z.; Wen, R.; Li, J.; Liang, X.; Jiang, G. Biomechanical Characteristics of Vertical Jumping of Preschool Children in China Based on Motion Capture and Simulation Modeling. Sensors 2021, 21, 8376. https://doi.org/10.3390/s21248376

Academic Editor: Christian Peham

Received: 31 October 2021

Accepted: 13 December 2021

Published: 15 December 2021

Publisher's Note: MDPI stays neutral with regard to jurisdictional claims in published maps and institutional affiliations.

Copyright: (c) 2021 by the authors. Licensee MDPI, Basel, Switzerland. This article is an open access article distributed under the terms and conditions of the Creative Commons Attribution (CC BY) license (https:// creativecommons.org/licenses/by/ $4.0 /)$.

\begin{abstract}
Vertical jumping is one of the basic motor skills, and it is an essential part of many sports. The main purpose of this paper is to investigate characteristics of vertical jumping of children. This paper uses a motion capture system, three-dimensional platforms, and a simulation modeling system to analyze the kinematics and dynamics performance of children's vertical jumping. The compression time increases from 3 to 4 years old, and flight height and time increases with age and stage gradually. In the compression phase and pushing phase, the hip and knee joint play a major role; in the landing phase, the knee and ankle joint play a major role. Muscle forces are mainly affected by age, and the three types of muscle force had two different trends. The muscle force of the shank and thigh increased with age, and the pelvic girdle muscles showed an "low-high-low" trend. The regression model suggests that the force of GMiP and the hip angular velocity have a great influence on jumping ability. Therefore, if we want to improve the jumping ability of preschool children, we should pay more attention to hip exercises. We should integrate the hip exercises into interesting games, which are more in line with their physical and mental health.
\end{abstract}

Keywords: biomechanical; preschool children; vertical jumping; motion capture; simulation modeling

\section{Introduction}

Vertical jumping is a typical stretch-shortening cycle movement (SSC), including preparatory lengthening and rapid shortening of the muscle-tendon unit (MTU) [1]. It is an essential part of many sports, such as basketball, volleyball, and gymnastics, and the performance of this motion directly affects the results of sporting events [2]. In the pyramid model of motor development proposed by Seefeldt [3], vertical jumping is located at the bottom of the pyramid and is the cornerstone of advanced motor skills.

In the preschool period, children's brains grow rapidly, their perception ability improves rapidly, and their neuromuscular system is developing gradually [4]. Therefore, this stage cannot be analyzed as one age group as a whole but should be subdivided into an age group every one year. The period from 3 to 6 years old is a key period for the development of basic motor skills; if children do not master basic motor skills in this period, the ability to learn complex skills in adulthood will be reduced greatly $[5,6]$. Some researchers also pay attention to the gender differences of vertical jumping, but studies show that there are no gender differences in this age group $[7,8]$.

At present, studies of vertical jumping focus on the following aspects: neuromuscular coordination, lower limb stiffness, joint dynamics, arm swing, and age characteristics. A research show adults have more feedforward muscle activity than boys when jumping on a single leg; the utilization efficiency of the stretch reflex and elastic potential energy is low in preadolescent children [9]. As age increases, the reflex response and joint-muscle stiffness of lower limb increase [10], and muscle co-contraction decreases [11]. Jumping patterns 
are different among children of different ages. In order to identify the characteristics of children's development, data from children are often compared with data from adults. Raffalt et al. [12] found children had more intra-subject variability in the intensity of their muscle activity, which indicated that muscle activity patterns of children are inconsistent, and considerable eccentric muscle contraction was involved in the pushing and landing phase, which limited the muscle activity. The performance of vertical jumping reflects the comprehensive development level of the whole body, but the neglect of longitudinal research of vertical jumping in preschool is shocking.

In the motor developmental field, researchers often use the motor development sequence to observe the development degree of basic movements, which is a qualitative research method; it describes the general characteristics and behavior patterns of children's movements, which is a fast method for classifying motor skill patterns appearing in the same stage. It can help teachers, parents, and researchers understand the motor development level, notice bottlenecks and key stages, and promote the healthy development of children's motor abilities $[13,14]$. At present, the research on vertical jumping pays more attention to the differences between different ages $[15,16]$ but ignores the research on the sequence of motor development.

In summary, this paper uses a motion capture system, two three-dimensional platforms, and a simulation modeling system to analyze the kinematics and dynamics performance of children's vertical jumping, and this study explore the different characteristics of children's vertical jumping at different ages and development stages. This paper features two innovations. Firstly, this is the first study to observe vertical jumping in relation to the characteristics of the age and developmental stages in preschool children. Secondly, an inverse dynamics simulation model analyzed the dynamic characteristics of children's lower limbs, and the 31 muscles' force of the lower limbs was accurately measured. The research hypotheses were as follows: (1) The characteristics of vertical jumping are different at different ages and development stages. (2) The ability of vertical jumping is mainly reflected in joint kinematics and muscle dynamics.

\section{Material and Methods}

\subsection{Participants}

Ninety preschool children (45 boys and 45 girls) were randomly recruited from a public kindergarten in Beijing. They were divided into a 3-year-old group (3 years $\leq$ age $<$ 4 years), a 4 -year-old group ( 4 years $\leq$ age $<5$ years), and a 5 -year-old group (5 years $\leq$ age $<6$ years). The inclusion criteria required typically developing children who understood the instructions and had good health and normal exercise ability. The exclusion criteria were physical development disorders, cognitive dysfunction diseases, skeletal muscle coordination diseases, etc. Prior to the experiment, the parents of subjects signed informed consent. The study was conducted in accordance with the Declaration of Helsinki, and the protocol was approved by the Ethics Committee of Psychology Department of Beijing Normal University (No. 201910210061). Basic information about the participants is shown in Table 1.

Table 1. Basic information about the participants $(\bar{X} \pm S)$.

\begin{tabular}{|c|c|c|c|c|}
\hline Age & $n$ & Height (cm) & Weight (kg) & BMI $\left(\mathrm{kg} / \mathrm{m}^{2}\right)$ \\
\hline 3 years old & 30 & $101.34 \pm 4.01$ & $16.62 \pm 2.00$ & $16.20 \pm 1.83$ \\
\hline 4 years old & 30 & $109.14 \pm 4.05^{\mathrm{a}}$ & $18.36 \pm 2.47^{\mathrm{a}}$ & $15.36 \pm 1.25$ \\
\hline 5 years old & 30 & $116.36 \pm 4.11^{\mathrm{ab}}$ & $22.38 \pm 3.95^{\mathrm{ab}}$ & $16.44 \pm 2.05$ \\
\hline
\end{tabular}

Notes: "a" means a significant difference compared with the 3-year-old group, and " $b$ " means a significant difference compared with the 4-year-old group. 


\subsection{Apparatus and Procedures}

\subsubsection{Experimental Preparation}

The subjects dressed in tight test clothing and pasted markers on their body joints according to the Plug-in-Gait lower limb model. Twenty-seven reflective markers were placed at the following anatomic location (Figure 1).

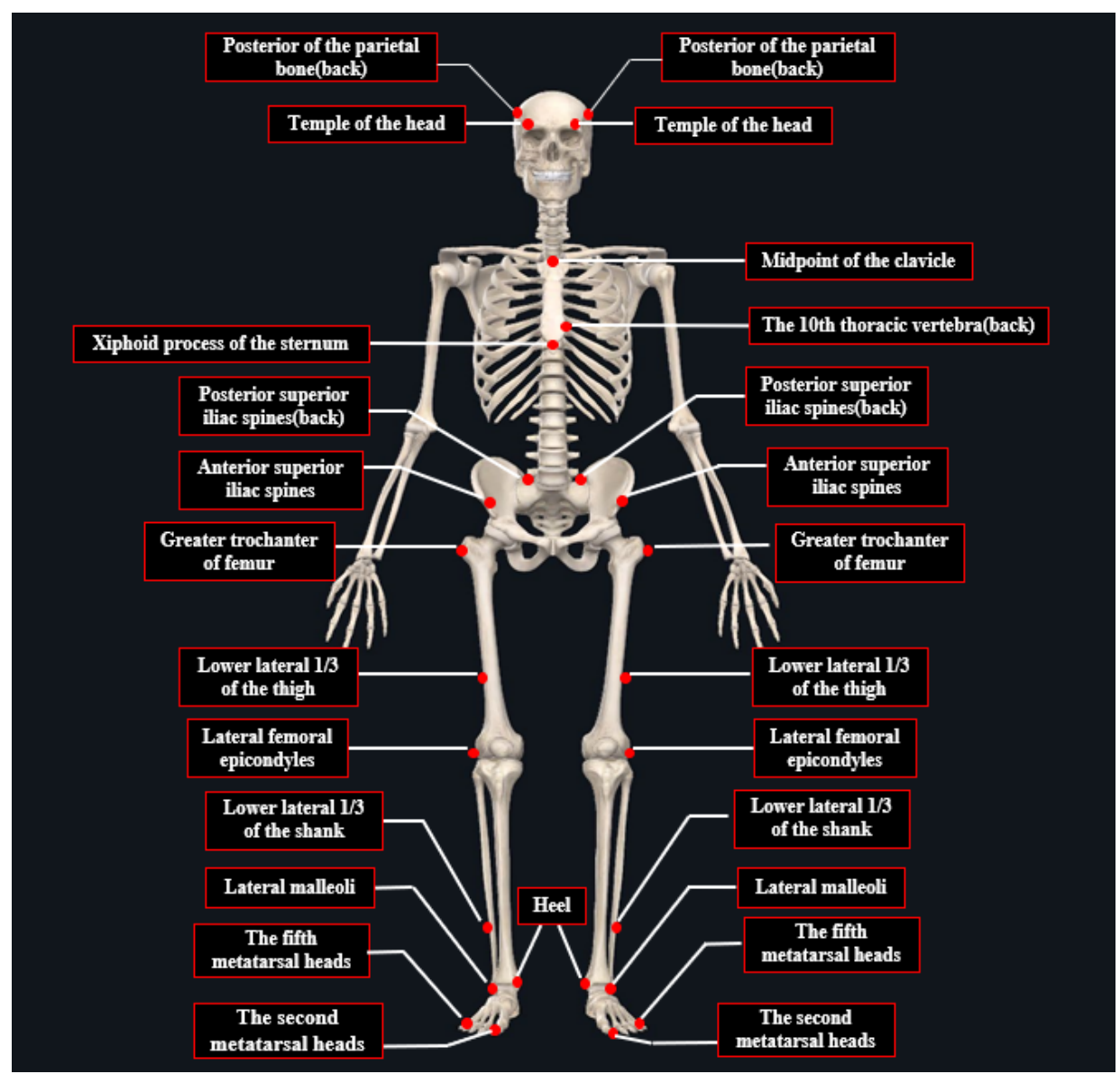

Figure 1. The anatomic location of the plug-in-gait lower limb model.

Prior to the test, morphological measurements were performed, such as height, weight, head length, thigh length, shank length, spine length, foot length pelvic width, knee width, and ankle width; these indicators were measured for simulation modeling. Participants warmed up for five minutes; then, subjects stood barefoot with one foot on a platform and another foot on the other platform. They jumped vertically in a way they found most comfortable. The subjects were required to perform in situ vertical jumping with their maximum strength three times, rest for 1 min after each jump, and jump again after the subjects adjust their state. After the test, the tester filters the data, selecting the data for which the capture of markers is the most completed. The kinematic and kinetic data were synchronized in the BTS motion capture software.

\subsubsection{Data Acquisition}

Kinematic data were collected using an eight-camera BTS motion capture system (SMART DX 700, Bioengineering Technology and Systems, Milano, Italy) sampling at $100 \mathrm{~Hz}$, which is used as action recognition. Kinetic data were collected by two force plates (KISTLER company, kistler928E, Winterthur, Switzerland) sampling at $250 \mathrm{~Hz}$, measured $0.6 \times 0.4 \times 0.2 \mathrm{~m}$. 


\subsubsection{Data Processing}

After the test, the vertical jumps were classified according to the developmental stages defined by Callahue [17]. The characteristics of motor development in each stage are as follows: (1) In the initial stage, the preparation position and crouch position are inconsistent, the body does not extend when taking off, the child lacks the ability to take off with both feet, and the height of the jump is very limited. (2) In the primary stage, the crouching angle of the knee joint is more than 90 degrees, the child takes off with both feet, the body is not fully extended, and the arms begin to assist in exertion and balance, lacking balance when landing. (3) In the mature stage, the crouching angle of the knee is between 60 and 90 degrees, the whole body is fully extended at takeoff, and the landing is controlled.

In this paper, vertical jumping was divided into five periods: (1) the compression phase: from upright to the maximum angle of a knee squat; (2) the pushing phase: from the maximum angle of a knee squat to feet off the ground; (3) the flight phase: from feet off the ground to feet on the ground; (4) the landing phase: from feet on the ground to the maximum angle of a knee squat; And (5) the standing phase: from the maximum angle of a knee squat to upright (Figure 2).

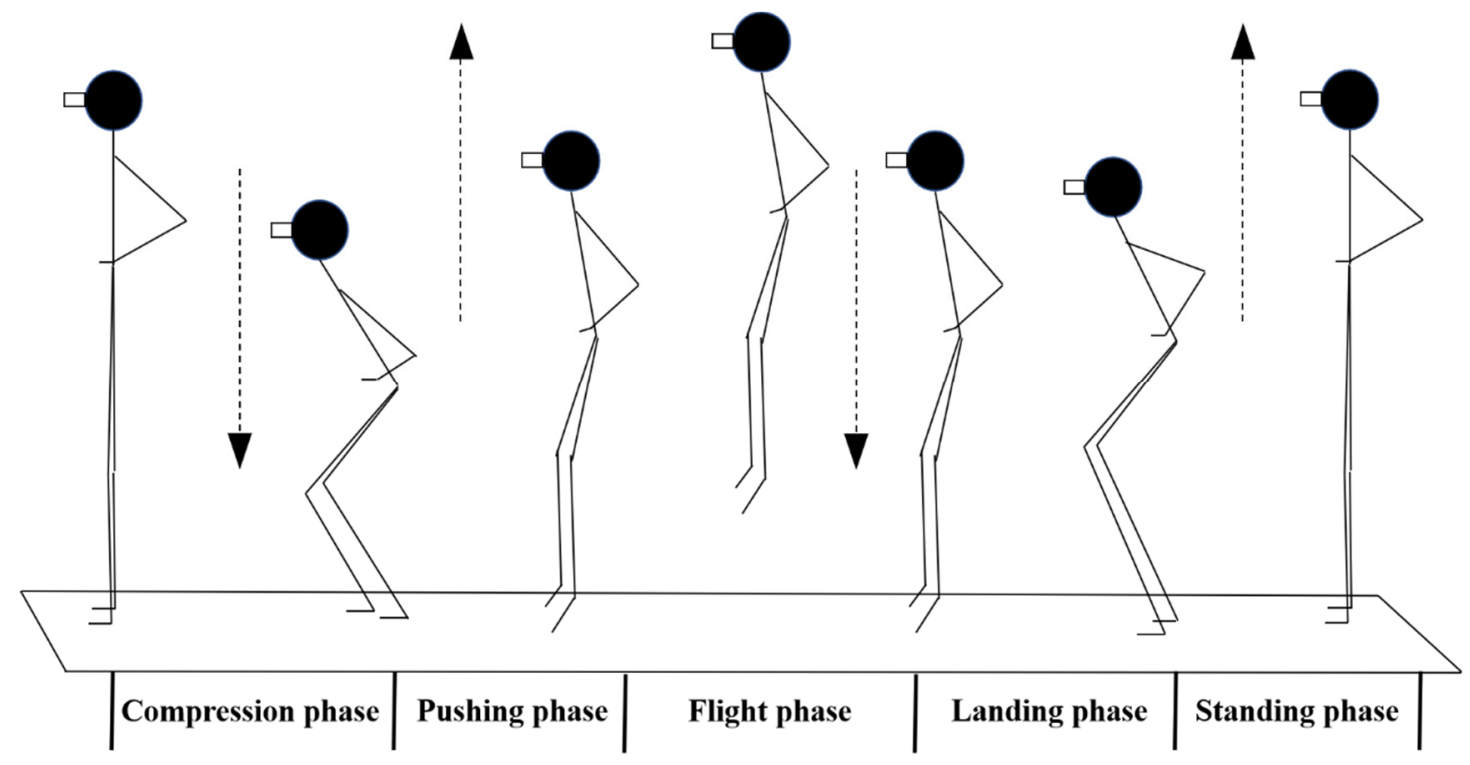

Figure 2. The phase of vertical jumping.

Marker trajectories were smoothed using a Butterworth filter with a $10 \mathrm{~Hz}$ cut-off, while kinetic data were filtered with a $20 \mathrm{~Hz}$ low-pass filter in SMART Analyzer software, the software can calculate spatiotemporal parameters and joint kinematic. The definition of kinematic and dynamic parameters in this paper are seen in Table 2.

\subsubsection{Anybody Simulation Operation}

The markers trajectory as a C3d format by SMART Tracker software and imported was exported into AnyBody7.0 (Anybody Technology, Aalborg, Denmark) software for simulation modeling analysis. Firstly, morphological measurements indicators of the subjects were input to the script file to establish a personalized simulation model for each subject. Secondly, the kinematic calculation was carried, and then the inverse dynamics calculation was conducted. The muscle force of the right lower limb of each subject was divided by their respective body weight for standardization, expressed by (N/BW). 
Table 2. Kinematic and dynamic parameters in vertical jumping.

\begin{tabular}{|c|c|c|}
\hline Parameters & Definition & Type \\
\hline Time of five phases & Time span of each movement phase & Spatiotemporal \\
\hline Squat depth & $\begin{array}{l}\text { The vertical downward distance of the midpoint of the posterior } \\
\text { superior iliac from upright to the maximum angle of a knee squat } \\
\text { during the compression phase }\end{array}$ & Spatiotemporal \\
\hline Flight height & $\begin{array}{l}\text { The vertical upward distance of the midpoint of the posterior superior } \\
\text { iliac from the upright to the highest point of the upward jump }\end{array}$ & Spatiotemporal \\
\hline Landing buffer depth & $\begin{array}{l}\text { The vertical downward distance of the midpoint of the posterior } \\
\text { superior iliac from upright to the maximum angle of a knee squat } \\
\text { during the landing phase }\end{array}$ & Spatiotemporal \\
\hline Maximum flexion angle of the hip & $\begin{array}{l}\text { The maximum angle between the anterior superior iliac spine, greater } \\
\text { trochanter of femur, and the lateral femoral epicondyles projected on } \\
\text { the sagittal plane }\end{array}$ & $\begin{array}{l}\text { Joint } \\
\text { parameters }\end{array}$ \\
\hline Maximum flexion angle of the knee & $\begin{array}{l}\text { The maximum angle between the greater trochanter of femur, the } \\
\text { lateral femoral epicondyles, and the lateral malleoli projected on the } \\
\text { sagittal plane }\end{array}$ & $\begin{array}{l}\text { Joint } \\
\text { parameters }\end{array}$ \\
\hline Maximum flexion angle of the ankle & $\begin{array}{l}\text { The maximum angle of the lateral femoral epicondyles, lateral malleoli, } \\
\text { and the fifth metatarsal head projected onto the sagittal plane }\end{array}$ & $\begin{array}{l}\text { Joint } \\
\text { parameters }\end{array}$ \\
\hline Maximum tilt angle of the spine & $\begin{array}{l}\text { The max angle between the line between the midpoint of the clavicle } \\
\text { and } \mathrm{T} 10 \text { projected onto the sagittal plane and the vertical axis }\end{array}$ & $\begin{array}{l}\text { Joint } \\
\text { parameters }\end{array}$ \\
\hline Hip range of motion & $\begin{array}{l}\text { The maximum flexion angle minus the minimum flexion angle during } \\
\text { the compression phase, pushing phase, and landing phase }\end{array}$ & $\begin{array}{l}\text { Joint } \\
\text { parameters }\end{array}$ \\
\hline Knee range of motion & $\begin{array}{l}\text { The maximum flexion angle minus the minimum flexion angle during } \\
\text { the compression phase, pushing phase, and landing phase }\end{array}$ & $\begin{array}{l}\text { Joint } \\
\text { parameters }\end{array}$ \\
\hline Ankle range of motion & $\begin{array}{l}\text { The maximum flexion angle minus the minimum flexion angle during } \\
\text { the compression phase, pushing phase, and landing phase }\end{array}$ & $\begin{array}{l}\text { Joint } \\
\text { parameters }\end{array}$ \\
\hline Angular velocity of the hip & Maximum angular velocity of the hip in the pushing phase & $\begin{array}{l}\text { Joint } \\
\text { parameters }\end{array}$ \\
\hline Angular velocity of the knee & Maximum angular velocity of the knee in the pushing phase & $\begin{array}{l}\text { Joint } \\
\text { parameters }\end{array}$ \\
\hline Angular velocity of the ankle & maximum angular velocity of the ankle in the pushing phase & $\begin{array}{l}\text { Joint } \\
\text { parameters }\end{array}$ \\
\hline Muscle force & Maximum muscle force of 31 lower-limb muscles & $\begin{array}{l}\text { Dynamic } \\
\text { parameters }\end{array}$ \\
\hline
\end{tabular}

The human body has a large number of muscles and is therefore prone to the problem of muscle redundancy, in which the number of muscles contained in the system is far greater than the number of muscles needed to balance the load. Muscle recruitment for inverse dynamics in simulation can be used to determine which muscles are involved in maintaining an external load in equilibrium. The optimization process of the skeletal muscle system in the AnyBody Modeling system is as follows [18-20]:

Objective function:

$$
G\left(f_{i}^{(M)}\right)
$$

Constraint condition:

$$
\begin{gathered}
C f=d \\
\geq 0, i \in\left\{1,2 \cdots n^{(M)}\right\}
\end{gathered}
$$

where $G$ is the assumed distribution strategy of the central nervous system to the muscle force, $C$ is the coefficient matrix of the equation, $f$ is the vector sum of unknown joint and muscle forces, and $D$ is the vector sum of known external and inertial forces. $f_{i}(M)$ 
represents the force of the $i$-th muscle; since the muscle can bear only tensile force, the value is $\geq 0$.

The form of muscle recruitment can be expressed by a polynomial:

$$
G=\sum_{i}\left(\frac{f_{i}^{(M)}}{N_{i}}\right)^{p}, p \geq 1
$$

$N_{i}$ is the current tensile strength of each muscle, and $p$ is a polynomial power function that can be set to different values according to different situations. The larger the power series, the greater the number of muscles involved in the equilibrium load, and the more significant the synergy is; the maximum synergistic effect occurs when all muscles work together. At this time, the maximum force of any muscle is as small as possible relative to the external load, which is the lowest physiological fatigue standard. The criteria for this recruitment method are as follows:

$$
G=\max \left(\frac{f_{i}^{(M)}}{N_{i}}\right), i \in\left\{1,2 \cdots n^{(M)}\right\}
$$

\subsection{Statistical Analysis}

Descriptive statistics (mean \pm standard deviation) were calculated for all data. Twoway ANOVAs were performed to examine the main effect of stage, the main effect of age, and the interaction effects of stage and age. The dependent variables are kinematic and dynamic parameters, and the independent variables are stage and age. The differences between groups were tested by LSD method. Linear regression was used to predict the parameters affecting jump ability, and the Stepwise method was used for statistical analysis. The dependent variable is flight height, and the independent variables are kinematic parameters during the compression phase, pushing phase, and muscle forces of the lower limb. SPSS 28.0 was used to analyze all data, and $p<0.05$ indicated significant differences.

\section{Results}

\subsection{Overall Development Characteristics}

Only 3-year-old boys have an initial development stage. Three-year-old girls are all in the primary stage. After 4 years (including 4 years old), the initial stage disappears, and the mature stage appears. Five-year-old children have maximum proportion in the mature stage (Figure 3).

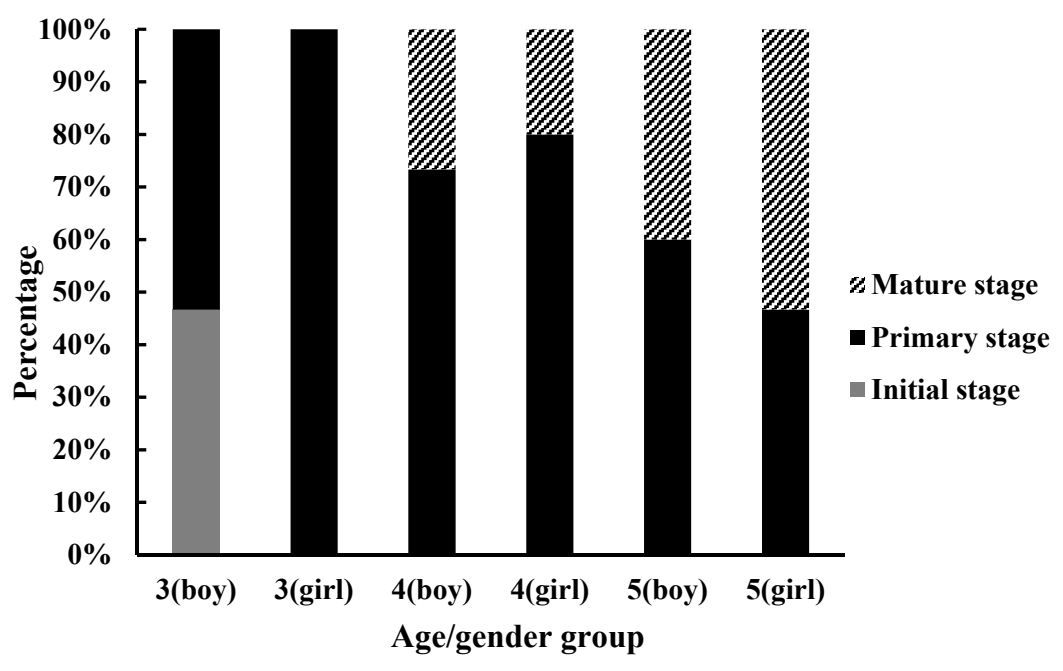

Figure 3. Proportion chart of motor development stages of children in different ages. 


\subsection{Kinematic Characteristics of Vertical Jumping in Children}

3.2.1. Spatiotemporal Parameters of Vertical Jumping

As shown in Table 3, significant differences occurred in compression time, flight time, and flight height.

Table 3. Results of main and interaction effect of spatiotemporal parameters.

\begin{tabular}{|c|c|c|c|c|}
\hline Dependent Variable & Main/Interaction Effect & $\mathbf{F}$ & Sig. & $\eta_{\text {partial }}^{2}$ \\
\hline \multirow{3}{*}{ Compression time } & Stage & 3.103 & 0.051 & 0.075 \\
\hline & Age & 5.349 & 0.007 & 0.122 \\
\hline & Stage $\times$ Age & 0.124 & 0.726 & 0.002 \\
\hline \multirow{3}{*}{ Pushing time } & Stage & 2.187 & 0.119 & 0.051 \\
\hline & Age & 1.736 & 0.183 & 0.041 \\
\hline & Stage $\times$ Age & 0.049 & 0.826 & 0.001 \\
\hline \multirow{3}{*}{ Flight time } & Stage & 5.695 & 0.005 & 0.122 \\
\hline & Age & 5.833 & 0.004 & 0.125 \\
\hline & Stage $\times$ Age & 2.034 & 0.158 & 0.024 \\
\hline \multirow{3}{*}{ Landing time } & Stage & 0.475 & 0.624 & 0.011 \\
\hline & Age & 1.657 & 0.197 & 0.039 \\
\hline & Stage $\times$ Age & 0.339 & 0.562 & 0.004 \\
\hline \multirow{3}{*}{ Standing time } & Stage & 0.283 & 0.754 & 0.007 \\
\hline & Age & 1.368 & 0.260 & 0.032 \\
\hline & Stage $\times$ Age & 0.257 & 0.614 & 0.003 \\
\hline \multirow{3}{*}{ Total time } & Stage & 1.765 & 0.178 & 0.041 \\
\hline & Age & 2.726 & 0.071 & 0.062 \\
\hline & Stage $\times$ Age & 0.037 & 0.847 & 0.000 \\
\hline \multirow{3}{*}{ Squat depth } & Stage & 2.583 & 0.082 & 0.059 \\
\hline & Age & 0.157 & 0.855 & 0.004 \\
\hline & Stage $\times$ Age & 0.464 & 0.497 & 0.006 \\
\hline \multirow{3}{*}{ Flight height } & Stage & 6.493 & 0.002 & 0.137 \\
\hline & Age & 10.704 & $<0.001$ & 0.207 \\
\hline & Stage $\times$ Age & 0.742 & 0.392 & 0.009 \\
\hline \multirow{3}{*}{ Buffer time } & Stage & 0.942 & 0.394 & 0.023 \\
\hline & Age & 0.112 & 0.894 & 0.003 \\
\hline & Stage $\times$ Age & 1.118 & 0.294 & 0.014 \\
\hline
\end{tabular}

AS shown in Figure 4, flight time and flight height have the main effects of stage and age and tend to increase gradually. Compression time has the main effect of age $(p<0.05)$.

\subsubsection{Joint Angle and Angular Velocity Parameters of Vertical Jumping}

As shown in Table 4, significant differences occurred in hip max flexion angle, spine max tilt angle, hip ROM in compression phase, knee ROM in pushing phase, knee ROM in landing phase, ankle ROM in landing phase, and hip max angular velocity in pushing phase. 

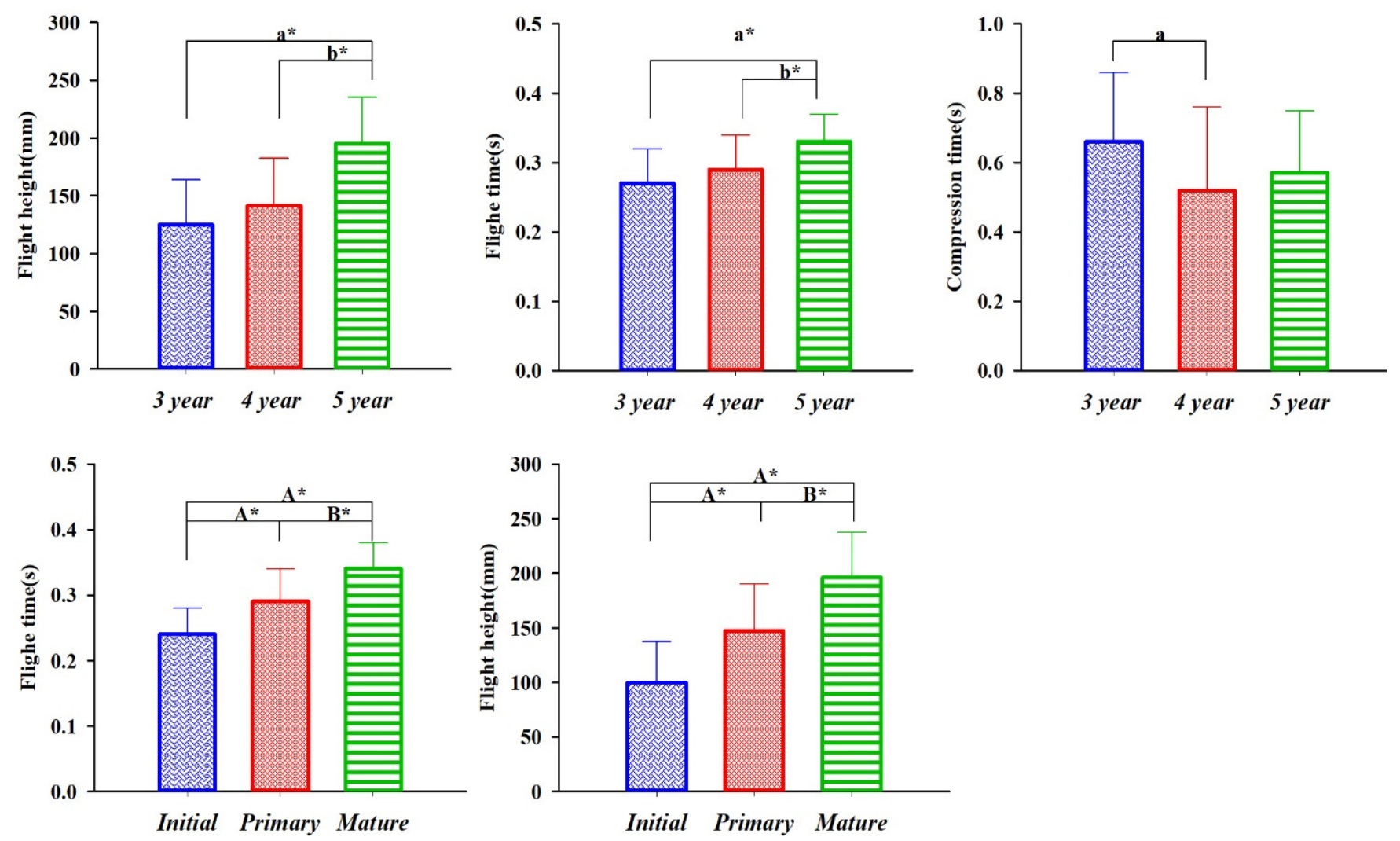

Figure 4. Results of main effect of spatiotemporal parameters. Notes: "a" means a significant difference compared with the 3-year-old group, " $a$ " means a very significant difference. " $b$ " means a very significant difference. A* means a very significant difference compared with the initial stage; $B^{*}$ means a very significant difference compared with the primary stage.

Table 4. Results of main and interaction effect of joint angle and angular velocity parameters.

\begin{tabular}{|c|c|c|c|c|}
\hline Dependent Variable & Main/Interaction Effect & $\mathbf{F}$ & Sig. & $\eta_{\text {partial }}{ }^{2}$ \\
\hline \multirow{3}{*}{ Ankle max flexion/extension (deg) } & Stage & 0.273 & 0.762 & 0.007 \\
\hline & Age & 0.956 & 0.389 & 0.023 \\
\hline & Stage $\times$ Age & 0.438 & 0.510 & 0.005 \\
\hline \multirow{3}{*}{ Knee max flexion/extension (deg) } & Stage & 2.329 & 0.104 & 0.057 \\
\hline & Age & 0.081 & 0.922 & 0.002 \\
\hline & Stage $\times$ Age & 0.642 & 0.425 & 0.008 \\
\hline \multirow{3}{*}{ Hip max flexion/extension (deg) } & Stage & 6.644 & 0.002 & 0.163 \\
\hline & Age & 2.008 & 0.142 & 0.056 \\
\hline & Stage $\times$ Age & 2.603 & 0.111 & 0.037 \\
\hline \multirow{3}{*}{ Spine max tilt (deg) } & Stage & 3.984 & 0.022 & 0.092 \\
\hline & Age & 0.248 & 0.781 & 0.006 \\
\hline & Stage $\times$ Age & 2.630 & 0.109 & 0.032 \\
\hline \multirow{3}{*}{ Knee ROM(deg)-compression phase } & Stage & 3.159 & 0.048 & 0.072 \\
\hline & Age & 0.350 & 0.706 & 0.009 \\
\hline & Stage $\times$ Age & 1.557 & 0.216 & 0.019 \\
\hline
\end{tabular}


Table 4. Cont.

\begin{tabular}{|c|c|c|c|c|}
\hline Dependent Variable & Main/Interaction Effect & $\mathbf{F}$ & Sig. & $\eta_{\text {partial }}{ }^{2}$ \\
\hline \multirow{3}{*}{ Ankle ROM(deg)-compression phase } & Stage & 0.256 & 0.775 & 0.006 \\
\hline & Age & 1.281 & 0.283 & 0.030 \\
\hline & Stage $\times$ Age & 0.201 & 0.655 & 0.002 \\
\hline \multirow{3}{*}{ Hip ROM (deg)-compression phase } & Stage & 3.552 & 0.033 & 0.083 \\
\hline & Age & 0.568 & 0.569 & 0.014 \\
\hline & Stage $\times$ Age & 1.195 & 0.278 & 0.015 \\
\hline \multirow{3}{*}{ Knee ROM (deg)-pushing phase } & Stage & 3.913 & 0.024 & 0.088 \\
\hline & Age & 0.112 & 0.894 & 0.003 \\
\hline & Stage $\times$ Age & 0.156 & 0.694 & 0.002 \\
\hline \multirow{3}{*}{ Ankle ROM (deg)-pushing phase } & Stage & 2.331 & 0.104 & 0.054 \\
\hline & Age & 0.647 & 0.526 & 0.016 \\
\hline & Stage $\times$ Age & 0.569 & 0.453 & 0.007 \\
\hline \multirow{3}{*}{ Hip ROM (deg)-pushing phase } & Stage & 3.053 & 0.053 & 0.070 \\
\hline & Age & 0.807 & 0.450 & 0.020 \\
\hline & Stage $\times$ Age & 0.019 & 0.890 & 0.000 \\
\hline \multirow{3}{*}{ Knee ROM (deg)-landing phase } & Stage & 3.771 & 0.027 & 0.085 \\
\hline & Age & 0.225 & 0.799 & 0.006 \\
\hline & Stage $\times$ Age & 0.458 & 0.501 & 0.006 \\
\hline \multirow{3}{*}{ Ankle ROM (deg)-landing phase } & Stage & 1.543 & 0.220 & 0.036 \\
\hline & Age & 4.556 & 0.013 & 0.100 \\
\hline & Stage $\times$ Age & 0.935 & 0.336 & 0.011 \\
\hline \multirow{3}{*}{ Hip ROM (deg)-landing phase } & Stage & 1.021 & 0.365 & 0.024 \\
\hline & Age & 0.054 & 0.947 & 0.001 \\
\hline & Stage $\times$ Age & 0.867 & 0.355 & 0.010 \\
\hline \multirow{3}{*}{$\begin{array}{c}\text { Knee max angular } \\
\text { velocity(rad/s)-pushing phase }\end{array}$} & Stage & 1.104 & 0.336 & 0.026 \\
\hline & Age & 1.829 & 0.167 & 0.043 \\
\hline & Stage $\times$ Age & 0.243 & 0.623 & 0.003 \\
\hline \multirow{3}{*}{$\begin{array}{c}\text { Ankle max angular } \\
\text { velocity(rad/s)-pushing phase }\end{array}$} & Stage & 0.103 & 0.902 & 0.003 \\
\hline & Age & 1.331 & 0.270 & 0.031 \\
\hline & Stage $\times$ Age & 0.677 & 0.413 & 0.008 \\
\hline \multirow{3}{*}{$\begin{array}{c}\text { Hip max angular } \\
\text { velocity(rad/s)-pushing phase }\end{array}$} & Stage & 1.314 & 0.274 & 0.031 \\
\hline & Age & 4.113 & 0.020 & 0.091 \\
\hline & Stage $\times$ Age & .238 & 0.627 & 0.003 \\
\hline
\end{tabular}

As shown in Tables 5 and 6, hip max flexion angle, spine max tilt angle, hip ROM in compression phase, knee ROM in pushing phase, knee ROM in landing phase, and ankle ROM (deg)-landing phase increase with stage. Ankle ROM in landing phase and hip max angular velocity in pushing phase increase with age.

Table 5. Results of stage effect of joint angle.

\begin{tabular}{cccc}
\hline Stage & Initial Stage & Primary Stage & Mature Stage \\
\hline Hip max flexion/extension (deg) & $84.042 \pm 10.909$ & $71.672 \pm 3.814$ & $50.902 \pm 6.781^{\mathrm{AB}}$ \\
Spine max tilt (deg) & $28.450 \pm 5.591$ & $33.693 \pm 1.803$ & $44.223 \pm 3.210^{\mathrm{AB}}$ \\
Hip ROM (deg)-compression phase & $77.184 \pm 10.413$ & $79.291 \pm 3.647$ & $97.198 \pm 6.458^{\mathrm{B}}$ \\
Knee ROM (deg)-pushing phase & $51.971 \pm 7.514$ & $55.756 \pm 2.617$ & $70.315 \pm 4.601^{\mathrm{AB}}$ \\
Knee ROM (deg)-landing phase & $21.236 \pm 3.942$ & $28.077 \pm 1.373$ & $35.403^{\mathrm{B}} \pm 2.414^{\mathrm{B}}$ \\
Ankle ROM (deg)-landing phase & $23.833 \pm 3.523$ & $34.001 \pm 1.218^{\mathrm{A}}$ & $39.317^{\mathrm{A}} \pm 2.157^{\mathrm{A}} \mathrm{B}$ \\
Hip max angular & $7.526 \pm 0.900$ & $9.395 \pm 0.311^{\mathrm{A}}$ & $10.463 \pm 0.551^{\mathrm{A}}$ \\
velocity(rad/s)-pushing phase & & & \\
\hline
\end{tabular}

Notes: A means a significant difference compared with the initial stage, $\mathrm{A}^{*}$ means a very significant difference. B means a significant difference compared with the primary stage. 
Table 6. Results of age effect of joint angle.

\begin{tabular}{ccrc}
\hline Age & 3 Years Old & 4 Years Old & 5 Years Old \\
\hline $\begin{array}{c}\text { Ankle ROM (deg)-landing phase } \\
\text { Hip max angular velocity(rad/s)-pushing } \\
\text { phase }\end{array}$ & $26.573 \pm 2.034$ & $36.027 \pm 2.012^{\mathrm{a}}$ & $39.634 \pm 1.706^{\mathrm{a}^{*}}$ \\
\hline
\end{tabular}

Notes: "a" means a significant difference compared with the 3-year-old group, "a*" means a very significant difference. " $\mathrm{b}$ " means a significant difference compared with the 4-year-old group.

\subsection{Peak Muscle Force of Vertical Jumping in Children}

As shown in Table 7, significant differences occurred in the following muscle: Soleus Medialis, Soleus Lateralis, Gastrocnemius Lateralis, Vastus Lateralis Inferior, Vastus Lateralis Superior, Vastus Medialis Mid, Vastus Medialis Superior, Vastus Intermedius, Rectus Femoris, Piriformis, Adductor Magnus Distal, Gemellus Inferior, Gemellus Superior, Obturator Internus, Poplitues, and Quadratus Femoris.

Table 7. Results of main and interaction effect of muscle force parameters.

\begin{tabular}{|c|c|c|c|c|}
\hline Dependent Variable & Main/Interaction Effect & $\mathbf{F}$ & Sig. & $\eta_{\text {partial }}{ }^{2}$ \\
\hline \multirow{3}{*}{ Soleus Medialis (SM) } & Stage & 2.582 & 0.082 & 0.058 \\
\hline & Age & 19.322 & $<0.001$ & 0.315 \\
\hline & Stage $\times$ Age & 1.952 & 0.166 & 0.023 \\
\hline \multirow{3}{*}{ Soleus Lateralis (SL) } & Stage & 0.726 & 0.487 & 0.017 \\
\hline & Age & 9.135 & $<0.001$ & 0.179 \\
\hline & Stage $\times$ Age & 0.719 & 0.399 & 0.008 \\
\hline \multirow{3}{*}{$\begin{array}{l}\text { Gastrocnemius Lateralis } \\
\text { (GL) }\end{array}$} & Stage & 0.081 & 0.923 & 0.002 \\
\hline & Age & 6.171 & 0.003 & 0.128 \\
\hline & Stage $\times$ Age & 0.403 & 0.527 & 0.005 \\
\hline \multirow{3}{*}{$\begin{array}{l}\text { Gastrocnemius Medialis } \\
\text { (GM) }\end{array}$} & Stage & 0.982 & 0.379 & 0.023 \\
\hline & Age & 2.878 & 0.062 & 0.064 \\
\hline & Stage $\times$ Age & 0.000 & 0.992 & 0.000 \\
\hline \multirow{3}{*}{ Peroneus Brevis (PB) } & Stage & 1.247 & 0.293 & 0.029 \\
\hline & Age & 2.922 & 0.059 & 0.065 \\
\hline & Stage $\times$ Age & 0.111 & 0.740 & 0.001 \\
\hline \multirow{3}{*}{ Peroneus Longus (PL) } & Stage & 0.590 & 0.557 & 0.014 \\
\hline & Age & 1.791 & 0.173 & 0.041 \\
\hline & Stage $\times$ Age & 0.835 & 0.363 & 0.010 \\
\hline \multirow{3}{*}{$\begin{array}{l}\text { Vastus Lateralis Inferior } \\
\text { (VLI) }\end{array}$} & Stage & 3.407 & 0.038 & 0.075 \\
\hline & Age & 3.042 & 0.053 & 0.068 \\
\hline & Stage $\times$ Age & 2.254 & 0.137 & 0.026 \\
\hline \multirow{3}{*}{$\begin{array}{l}\text { Vastus Lateralis } \\
\text { Superior (VLS) }\end{array}$} & Stage & 0.788 & 0.458 & 0.018 \\
\hline & Age & 13.694 & $<0.001$ & 0.246 \\
\hline & Stage $\times$ Age & 0.007 & 0.934 & 0.000 \\
\hline \multirow{3}{*}{$\begin{array}{l}\text { Vastus Medialis Inferior } \\
\text { (VMI) }\end{array}$} & Stage & 1.943 & 0.150 & 0.044 \\
\hline & Age & 3.177 & 0.047 & 0.070 \\
\hline & Stage $\times$ Age & 0.863 & 0.356 & 0.010 \\
\hline \multirow{3}{*}{$\begin{array}{l}\text { Vastus Medialis Mid } \\
\text { (VMM) }\end{array}$} & Stage & 1.254 & 0.291 & 0.029 \\
\hline & Age & 11.076 & $<0.001$ & 0.209 \\
\hline & Stage $\times$ Age & 0.002 & 0.965 & 0.000 \\
\hline \multirow{3}{*}{$\begin{array}{l}\text { Vastus Medialis } \\
\text { Superior (VMS) }\end{array}$} & Stage & 2.217 & 0.115 & 0.050 \\
\hline & Age & 6.475 & 0.002 & 0.134 \\
\hline & Stage $\times$ Age & 1.847 & 0.178 & 0.022 \\
\hline
\end{tabular}


Table 7. Cont.

\begin{tabular}{|c|c|c|c|c|}
\hline Dependent Variable & Main/Interaction Effect & $\mathbf{F}$ & Sig. & $\eta_{\text {partial }}{ }^{2}$ \\
\hline \multirow{3}{*}{ Vastus Intermedius (VI) } & Stage & 0.906 & 0.408 & 0.021 \\
\hline & Age & 10.510 & $<0.001$ & 0.200 \\
\hline & Stage $\times$ Age & 0.010 & 0.921 & 0.000 \\
\hline \multirow{3}{*}{ Rectus Femoris (RF) } & Stage & 1.174 & 0.314 & 0.027 \\
\hline & Age & 10.459 & $<0.001$ & 0.199 \\
\hline & Stage $\times$ Age & 1.946 & 0.167 & 0.023 \\
\hline \multirow{3}{*}{$\begin{array}{l}\text { Semitendinosus } \\
\qquad(\mathrm{Sd})\end{array}$} & Stage & 0.707 & 0.496 & 0.017 \\
\hline & Age & 2.821 & 0.065 & 0.063 \\
\hline & Stage $\times$ Age & 0.117 & 0.733 & 0.001 \\
\hline \multirow{3}{*}{ Semimembranosus (Sb) } & Stage & 1.755 & 0.179 & 0.040 \\
\hline & Age & 0.654 & 0.522 & 0.015 \\
\hline & Stage $\times$ Age & 1.247 & 0.267 & 0.015 \\
\hline \multirow{3}{*}{$\begin{array}{c}\text { Biceps Femoris } \\
\text { CaputLongum (BFCL) }\end{array}$} & Stage & 0.896 & 0.412 & 0.021 \\
\hline & Age & 1.263 & 0.288 & 0.029 \\
\hline & Stage $\times$ Age & 0.274 & 0.602 & 0.003 \\
\hline \multirow{3}{*}{$\begin{array}{l}\text { Gluteus Minimus } \\
\text { Anterior (GMiA) }\end{array}$} & Stage & 0.162 & 0.850 & 0.004 \\
\hline & Age & 0.703 & 0.498 & 0.016 \\
\hline & Stage $\times$ Age & 0.541 & 0.464 & 0.006 \\
\hline \multirow{3}{*}{$\begin{array}{l}\text { Gluteus Minimus Mid } \\
\text { (GMiM) }\end{array}$} & Stage & 0.637 & 0.531 & 0.015 \\
\hline & Age & 0.181 & 0.835 & 0.004 \\
\hline & Stage $\times$ Age & 0.000 & 0.983 & 0.000 \\
\hline \multirow{3}{*}{$\begin{array}{l}\text { Gluteus Minimus } \\
\text { Posterior (GMiP) }\end{array}$} & Stage & 0.553 & 0.577 & 0.013 \\
\hline & Age & 2.541 & 0.085 & 0.057 \\
\hline & Stage $\times$ Age & 1.201 & 0.276 & 0.014 \\
\hline \multirow{3}{*}{$\begin{array}{l}\text { Gluteus Medius } \\
\text { Anterior (GMeA) }\end{array}$} & Stage & 1.039 & 0.358 & 0.024 \\
\hline & Age & 0.466 & 0.629 & 0.011 \\
\hline & Stage $\times$ Age & 0.121 & 0.728 & 0.001 \\
\hline \multirow{3}{*}{$\begin{array}{l}\text { Gluteus Medius } \\
\text { Posterior (GMeP) }\end{array}$} & Stage & 0.295 & 0.745 & 0.007 \\
\hline & Age & 2.952 & 0.058 & 0.066 \\
\hline & Stage $\times$ Age & 0.511 & 0.477 & 0.006 \\
\hline \multirow{3}{*}{$\begin{array}{l}\text { Gluteus Maximus } \\
\text { Superior (GMaS) }\end{array}$} & Stage & 0.814 & 0.446 & 0.019 \\
\hline & Age & 2.323 & 0.104 & 0.052 \\
\hline & Stage $\times$ Age & 4.054 & 0.047 & 0.046 \\
\hline \multirow{3}{*}{$\begin{array}{l}\text { Gluteus Maximus } \\
\text { Inferior (GMaI) }\end{array}$} & Stage & 1.527 & 0.223 & 0.035 \\
\hline & Age & 2.616 & 0.079 & 0.059 \\
\hline & Stage $\times$ Age & 1.946 & 0.167 & 0.023 \\
\hline \multirow{3}{*}{ Piriformis (Pir) } & Stage & 2.156 & 0.122 & 0.049 \\
\hline & Age & 4.703 & 0.012 & 0.101 \\
\hline & Stage $\times$ Age & 0.549 & 0.461 & 0.006 \\
\hline \multirow{3}{*}{$\begin{array}{l}\text { Adductor Magnus } \\
\text { Distal (AMD) }\end{array}$} & Stage & 3.975 & 0.022 & 0.086 \\
\hline & Age & 4.586 & 0.013 & 0.098 \\
\hline & Stage $\times$ Age & 1.419 & 0.237 & 0.017 \\
\hline \multirow{3}{*}{$\begin{array}{l}\text { Adductor Magnus Mid } \\
\text { (AMM) }\end{array}$} & Stage & 1.644 & 0.199 & 0.038 \\
\hline & Age & 1.702 & 0.189 & 0.039 \\
\hline & Stage $\times$ Age & 0.393 & 0.532 & 0.005 \\
\hline \multirow{3}{*}{ Gemellus Inferior (GI) } & Stage & 0.407 & 0.667 & 0.010 \\
\hline & Age & 8.714 & $<0.001$ & 0.172 \\
\hline & Stage $\times$ Age & 0.118 & 0.733 & 0.001 \\
\hline \multirow{3}{*}{ Gemellus Superior (GS) } & Stage & 0.002 & 0.998 & 0.000 \\
\hline & Age & 8.935 & $<0.001$ & 0.175 \\
\hline & Stage $\times$ Age & 0.018 & 0.895 & 0.000 \\
\hline
\end{tabular}


Table 7. Cont.

\begin{tabular}{ccccc}
\hline Dependent Variable & Main/Interaction Effect & F & Sig. & $\boldsymbol{\eta}_{\text {partial }}{ }^{2}$ \\
\hline \multirow{2}{*}{ Obturator Internus (OI) } & Stage & 0.495 & 0.612 & 0.012 \\
& Age & 11.771 & $<0.001$ & 0.219 \\
& Stage $\times$ Age & 0.022 & 0.883 & 0.000 \\
\hline \multirow{2}{*}{ Poplitues (Pop) } & Stage & 2.610 & 0.079 & 0.059 \\
& Age & 6.969 & 0.002 & 0.142 \\
& Stage $\times$ Age & 1.455 & 0.231 & 0.017 \\
\hline \multirow{3}{*}{ Quadratus Femoris (QF) } & Stage & 1.270 & 0.286 & 0.029 \\
& Age & 9.616 & $<0.001$ & 0.186 \\
& Stage $\times$ Age & 2.150 & 0.146 & 0.025 \\
\hline
\end{tabular}

As shown in Tables 8 and 9, the muscle forces of SM, SL, GL, VLS, VMM, VMS, VI, RF, Pir, AMD, GI, GS, OI, Popliteus, and QF increase with age. The muscle forces of VLI and AMD increase with stage.

Table 8. Results of age effect of muscle force.

\begin{tabular}{cccc}
\hline Age & 3 Years Old & 4 Years Old & 5 Years Old \\
\hline SM & $4.152 \pm 1.508$ & $4.356 \pm 1.054$ & $6.716 \pm 2.550 \mathrm{a}^{*} \mathrm{~b}^{*}$ \\
SL & $8.668 \pm 2.567$ & $11.968 \pm 3.717 \mathrm{a}^{*}$ & $13.620 \pm 4.14 \mathrm{a}^{*}$ \\
GL & $5.055 \pm 1.915$ & $6.965 \pm 2.283 \mathrm{a}^{\mathrm{a}^{*}}$ & $7.321 \pm 2.38 \mathrm{a}^{\mathrm{a}^{*}}$ \\
VLS & $14.469 \pm 5.507$ & $14.347 \pm 3.717$ & $22.990 \pm 7.667 \mathrm{a}^{*} \mathrm{~b}^{*}$ \\
VMM & $3.087 \pm 1.459$ & $3.534 \pm 0.973$ & $5.325 \pm 1.792 \mathrm{a}^{*} \mathrm{~b}^{*}$ \\
VMS & $3.033 \pm 1.302$ & $3.524 \pm 1.282$ & $4.919 \pm 1.576^{\mathrm{a}^{*} \mathrm{~b}^{*}}$ \\
VI & $4.502 \pm 1.494$ & $4.500 \pm 1.153$ & $6.684 \pm 2.210^{\mathrm{a}^{*} \mathrm{~b}^{*}}$ \\
RF & $3.498 \pm 1.057$ & $3.422 \pm 1.625$ & $4.330 \pm 2.230 \mathrm{a}^{*} \mathrm{~b}^{*}$ \\
Pir & $1.337 \pm 0.804$ & $1.948 \pm 1.010^{\mathrm{a}}$ & $1.742 \pm 0.786$ \\
AMD & $3.813 \pm 1.129$ & $3.554 \pm 1.219$ & $4.866 \pm 1.963 \mathrm{ab}^{*}$ \\
GI & $0.459 \pm 0.205$ & $0.784 \pm 0.365 \mathrm{a}^{\mathrm{a}}$ & $0.545 \pm 0.278 \mathrm{~b}^{*}$ \\
GS & $0.366 \pm 0.165$ & $0.586 \pm 0.187 \mathrm{a}^{*}$ & $0.428 \pm 0.2055^{\mathrm{b}}$ \\
OI & $2.430 \pm 1.063$ & $4.396 \pm 1.415 \mathrm{a}^{*}$ & $3.242 \pm 1.623 \mathrm{ab}^{*}$ \\
Pop & $0.538 \pm 0.223$ & $0.574 \pm 0.270$ & $0.921 \pm 0.368 \mathrm{a}^{*} \mathrm{~b}^{*}$ \\
QF & $1.231 \pm 0.431$ & $2.125 \pm 0.790 \mathrm{a}^{*}$ & $1.597 \pm 0.991 \mathrm{~b}^{\mathrm{b}}$ \\
\hline
\end{tabular}

Notes: "a" means a significant difference compared with the 3-year-old group, " $a *$ " means a very significant difference. " $b$ " means a significant difference compared with the 4-year-old group, " $b$ *" means a very significant difference compared with the 4-year-old group.

Table 9. Results of stage effect of muscle force.

\begin{tabular}{cccc}
\hline Stage & Initial Stage & Primary Stage & Mature Stage \\
\hline VLI & $0.613 \pm 0.181$ & $0.739 \pm 0.341$ & $1.066 \pm 0.394^{\mathrm{A}^{*} \mathrm{~B}^{*}}$ \\
AMD & $3.506 \pm 1.734$ & $3.778 \pm 0.173$ & $5.151 \pm 0.166^{\mathrm{AB}}$ \\
\hline
\end{tabular}

Notes: A means a significant difference compared with the initial stage, $A^{*}$ means a very significant difference. $B$ means a significant difference compared with the primary stage, $\mathrm{B}^{*}$ means a very significant difference compared with the primary stage.

\subsection{Influencing Factors of Jumping Ability of Preschool Children}

Linear regression was used to predict the parameters affecting jump ability. Data display that ankle ROM in pushing phase, spine max tilt angle, hip max angular velocity, muscle force of GMiP, and muscle force of GM were incorporated into the model. The final regression equation is:

$$
\begin{gathered}
\mathrm{Y}=-85.527+1.243 * \text { ankle } \mathrm{ROM}+0.754 * \text { spine max tilt angle }+9.354 * \\
\text { hip max angular velocity }+33.847 * \mathrm{GMiP}+2.640 * \mathrm{GM}
\end{gathered}
$$


The higher the number before the indicator, the greater the influence on the dependent variable. VIF is the variance expansion coefficient; when the value is less than 3 , it indicates that there is no collinearity problem; when Durbin-Watson's value is between $1.5-2.5$, it indicates that there is no self-correlation between samples, and the values of VIF and DW are within a reasonable range. $R^{2}$ indicates that the regression model could explain $64.1 \%$ of the variance of the dependent variable (Table 10).

Table 10. Regression analysis of influencing factors of vertical jumping.

\begin{tabular}{|c|c|c|c|c|c|c|c|c|c|c|}
\hline \multirow{2}{*}{$\begin{array}{l}\text { Dependent } \\
\text { Variable }\end{array}$} & \multirow[t]{2}{*}{ Model } & \multicolumn{2}{|c|}{$\begin{array}{l}\text { Unstandardized } \\
\text { Coefficients }\end{array}$} & \multicolumn{3}{|c|}{ Standardized Coefficients } & \multicolumn{2}{|c|}{ Collinearity } & \multirow{2}{*}{$\begin{array}{l}\text { Durbin- } \\
\text { Watson }\end{array}$} & \multirow[t]{2}{*}{$\mathbf{R}^{2}$} \\
\hline & & B & Std. Error & Beta & $\mathbf{t}$ & Sig. & Tolerance & VIF & & \\
\hline \multirow{6}{*}{$\begin{array}{l}\text { Flight } \\
\text { height } \\
(\mathrm{mm})\end{array}$} & (Constant) & -85.527 & 24.132 & & -3.544 & $<0.001$ & & & \multirow{4}{*}{1.876} & \multirow{4}{*}{0.641} \\
\hline & $\begin{array}{c}\text { Ankle ROM(deg)-pushing } \\
\text { phase }\end{array}$ & 1.243 & 0.307 & 0.319 & 4.044 & $<0.001$ & 0.931 & 1.074 & & \\
\hline & Spine max tilt angle(deg) & 0.754 & 0.292 & 0.212 & 2.577 & 0.012 & 0.852 & 1.174 & & \\
\hline & $\begin{array}{c}\text { Hip max angular } \\
\text { velocity(rad/s)-pushing } \\
\text { phase }\end{array}$ & 9.354 & 2.007 & 0.392 & 4.660 & $<0.001$ & 0.819 & 1.221 & & \\
\hline & $\begin{array}{l}\text { Gluteus Minimus Posterior } \\
\qquad(\mathrm{GMiP})\end{array}$ & 33.847 & 7.657 & 0.341 & 4.420 & $<0.001$ & 0.974 & 1.027 & & \\
\hline & $\begin{array}{l}\text { Gastrocnemius Medialis } \\
\text { (GM) }\end{array}$ & 2.640 & 1.203 & 0.171 & 2.195 & 0.032 & 0.953 & 1.049 & & \\
\hline
\end{tabular}

\section{Discussion}

The main purpose of this paper is to investigate characteristics of vertical jumping of children. The spatial and temporal parameters, joint kinematics, and muscle forces of the lower limb were evaluated. As motor development matured and age increased, most of the indicators showed an increasing linear trend, while the muscle force of the pelvic girdle showed an "low-high-low" trend. This paper uses flight height to evaluate ability of children's vertical jumping. Finally, a regression equation is established, which reflects the influence of different factors on flight height.

In spatiotemporal parameters of vertical jumping, from 3 to 4 years old, the compression time increase, it means the 4year-old children move faster. The flight height and time increases with age and stage gradually. It is related to the increase of lower-limb muscle force, which is consistent with previous studies [21]. Joint kinematics data show that the mature stage has greater joint motion, and the differences are mainly reflected in the compression phase, pushing phase, and stability phase. In the compression phase and pushing phase, the hip and knee joint play a major role, and they work together to promote the take-off. In the landing phase, the knee and ankle joint play a major role, and they work together to ensure a stable landing. Many studies have proposed that the knee is the most important joint in generating energy for jumping [22,23]. Harrison et al. [24] observed that more movement of knee and effective use of knee extensor are the signs of a mature vertical jump mode. In the compression phase, adults produce more energy from the knee, but the hip and knee are equally important during the pushing phase, and the utilization rate of the hip is significantly lower in children [25]. With the increase of age, the motion parameters also show an increasing trend, mainly reflected in the hip angular velocity in pushing phase and the ankle ROM in landing phase.

Muscle forces are mainly affected by age. The data mainly include three muscle types: (1) muscles in the back of the shank: SM, SL, and GL, which are responsible for the flexion of knee and ankle.;(2) muscles in the front of the thigh: VLI, VMM, VMS, VI, and RF, which are responsible for the flexion of hip; And (3) muscles of the pelvic girdle: Pir, AMD, GI, GS, OI, Pop, and QF, which are responsible for stabilizing the pelvis. In this study, the maximum muscle force was VLS; however, a simulation study on adults found that [26] the gluteal muscle is the most powerful muscle, which reflects the difference 
between children and adults. Due to their young age and incomplete muscle development, children do not know how to coordinate muscle force. Yahya et al. [27] studied the jumping movement of basketball players, and they found that the main muscle used in jumping was semitendinosus, which was inconsistent with the results of our article; the reason may be that the research objects are different, and the jumping movements involved in basketball are different in this experiment. In this study, the three types of muscle forces have two different trends. The muscle forces of shank and thigh increase with age, and the pelvic girdle muscles show a "low-high-low" trend.

Vertical jumping is evaluated by the height of flight [28]. Relevant studies found that the flight height is affected by age and development stage [6]. However, what motion characteristics affect the flight height? There is no research on this issue. Therefore, this paper verifies which factors have an impact on flight height and the degree of impact. The data suggest that the force of GMiP and the hip angular velocity have a great influence on it. Therefore, if we want to improve the jumping ability of preschool children, we should pay more attention to hip exercise. Children at this age do not adapt to high-intensity sports training [29]; the hip exercise should be integrated into interesting games, which are more in line with their physical and mental health.

Limitations:

There are some limitations to this study. First, this paper does not analyze the gender differences of preschool children. Second, kinematic parameters only study the motion data of sagittal plane but lack the frontal plane and horizontal plane. In future research, the discussion of gender factors should be added, and more comprehensive kinematic data should be added.

\section{Conclusions}

Both developmental stage and age have an impact on the characteristics of vertical jumping of preschool children, but they have no interactive effect. Older children and children in the mature stage have more flexible joints, and the range of motion is greater, so it generates more joint motion. In the compression phase and pushing phase, the hip and knee joint play a major role; in the landing phase, the knee and ankle joint play a major role. The difference of muscle force is reflected in muscles in the back of the shank, muscles in the front of the thigh, and the muscles of the pelvic girdle. Muscle forces of the shank and thigh increase with age, and muscle forces of the pelvic girdle show an "low-high-low" trend. The regression model suggests that the muscle force of GMiP and the hip angular velocity have a great influence on jumping ability. Therefore, if we want to improve the jumping ability of preschool children, we should pay more attention to hip exercise. We should integrate the hip exercise into interesting games, which are more in line with their physical and mental health.

Author Contributions: Modeling conceptualization, P.Z., R.W.; writing—review and editing, P.Z.; funding acquisition, G.J.; methodology, Z.J.; data curation, Z.J. and G.J.; original draft preparation, J.L. and X.L. All authors have read and agreed to the published version of the manuscript.

Funding: This work was supported by the National Social Science Foundation of China in 2020 under Grant No. 20BTY070.

Institutional Review Board Statement: The study was conducted according to the guidelines of the Declaration of Helsinki and approved by the Ethics Committee of Psychology Department, Beijing Normal University (201910210061).

Informed Consent Statement: The parents of all participants in the study signed the informed consent.

Data Availability Statement: The data presented in this study are available on request from the corresponding author.

Acknowledgments: The authors thank the teachers of the P. E. Institute of Beijing Normal University for their help with testing and also thank the teachers from the kindergarten. 
Conflicts of Interest: The authors declare no conflict of interest.

\section{References}

1. Bobbert, M.F.; Casius, L.J. Is the effect of a countermovement on jump height due to active state development? Med. Sci. Sport Exerc. 2005, 37, 440-446. [CrossRef]

2. Salaj, S.; Markovic, G. Specificity of jumping, sprinting, and quick change-of-direction motor abilities. J. Strength Cond. Res. 2011, 25, 1249-1255. [CrossRef]

3. Seefeldt, V. Physical Fitness in Preschool and Elementary School-Aged Children. Am. Phys. Educ. Rev. 1984, 55, 33-40. [CrossRef]

4. Payne, G.; Peixin, G.; Guoli, L. Introduction to Human Motor Development; People's Education Press: Beijing, China, 2008.

5. Lloyd, R.S.; Oliver, J.L.; Hughes, M.G.; Williams, C.A. Reliability and validity of field-based measures of leg stiffness and reactive strength index in youths. J. Sports Sci. 2009, 27, 1565-1573. [CrossRef]

6. Lazaridis, S.N.; Bassa, E.I.; Patikas, D.; Hatzikotoulas, K.; Lazaridis, F.K.; Kotzamanidis, C.M. Biomechanical comparison in different jumping tasks between untrained boys and men. Pediatr. Exerc. Sci. 2013, 25, 101-113. [CrossRef] [PubMed]

7. Swartz, E.E.; Decoster, L.C.; Russell, P.J.; Croce, R.V. Effects of Developmental Stage and Sex on Lower Extremity Kinematics and Vertical Ground Reaction Forces during Landing. J. Athl. Train. 2005, 40, 9-14.

8. Jones, C.M.; Mcnarry, M.A.; Owen, N.J. The effect of body size on countermovement jump kinetics in children aged 72-11 years. Eur. J. Sport Sci. 2020, 20, 174-181. [CrossRef] [PubMed]

9. Oliver, J.L.; Smith, P.M. Neural control of leg stiffness during hopping in boys and men. J. Electromyogr. Kinesiol. 2010, 20, 973-979. [CrossRef] [PubMed]

10. Grosset, J.F.; Mora, I.; Lambertz, D.; Pérot, C. Changes in stretch reflexes and muscle stiffness with age in prepubescent children. J. Appl. Physiol. 2007, 102, 2352-2360. [CrossRef] [PubMed]

11. Lambertz, D.; Mora, I.; Grosset, J.F.; Perot, C. Evaluation of musculotendinous stiffness in prepubertal children and adults, taking into account muscle activity. J. Appl. Physiol. 2003, 95, 64-72. [CrossRef]

12. Raffalt, P.C.; Alkjaer, T.; Simonsen, E.B. Intra-subject variability in muscle activity and co-contraction during jumps and landings in children and adults. Scand. J. Med. Sci. Sports 2017, 27, 820-831. [CrossRef]

13. Seefeldt, V.; Haubenstricker, J. Patterns, phases, or stages: An analytical model for the study of developmental movement. In The development of Movement Control and Coordination; John Wiley \& Sons, Ltd.: New York, NJ, USA, 1982; pp. 309-318.

14. Halverson, L.E.; Williams, K. Development sequences for hopping over distance: A pre-longitudinal screening. Res. Q. Exerc. Sport 1985, 56, 37-44. [CrossRef]

15. Sgrò, F.; Nicolosi, S.; Schembri, R.; Pavone, M.; Lipoma, M. Assessing vertical jump developmental levels in childhood using a low-cost motion capture approach. Percept. Mot. Ski. 2015, 120, 642-658. [CrossRef]

16. Lacquaniti, F.; Ivanenko, Y.P.; Zago, M. Development of human locomotion. Curr. Opin. Neurobiol. 2012, 22, 822-828. [CrossRef]

17. Callahue, D.L.; Ozmun, J.C.; Goodway, J.D. Understanding Motor Development: Infants, Children, Adolescents, Adults, 7th ed.; McGraw-Hill: New York, NY, USA, 2012; pp. 10-11.

18. Damsgaard, M.; Rasmussen, J.; Christensen, S.T.; Surma, E.; Zee, M.D. Analysis of musculoskeletal systems in the AnyBody Modeling System. Simul. Model. Pract. Theory 2006, 14, 1100-1111. [CrossRef]

19. Trinler, U.; Schwameder, H.; Baker, R.; Alexander, N. Muscle force estimation in clinical gait analysis using AnyBody and OpenSim. J. Biomech. 2019, 86, 55-63. [CrossRef]

20. Pang, B.; Ji, Z.; Zhang, Z.; Sun, Y.; Ma, C.; He, Z.; Hu, X.; Jiang, G. Strength Training Characteristics of Different Loads Based on Acceleration Sensor and Finite Element Simulation. Sensors 2021, 21, 647. [CrossRef]

21. Chen, L. Kinematical Research on Skill of 9-18 Years Old Junior Students Standing Vertical Jump. China Sport Sci. Technol. 2008, 44, 67-70.

22. Hubley, C.L.; Wells, R.P. A work-energy approach to determine individual joint contributions to vertical jump performance. Eur. J. Appl. Physiol. Occup. Physiol. 1983, 50, 247-254. [CrossRef]

23. Ravn, S.; Voigt, M.; Simonsen, E.B.; Alkjaer, T.; Bojsen-Møller, F.; Klausen, K. Choice of jumping strategy in two standard jumps, squat and countermovement jump-effect of training background or inherited preference? Scand. J. Med. Sci. Sports 1999, 9, 201-208. [CrossRef]

24. Harrison, A.J.; Ryan, W.; Hayes, K. Functional data analysis of joint coordination in the development of vertical jump performance. Sports Biomech. 2007, 6, 199-214. [CrossRef] [PubMed]

25. Raffalt, P.C.; Alkjær, T.; Simonsen, E.B. Joint dynamics and intra-subject variability during countermovement jumps in children and adults. J. Biomech. 2016, 49, 2968-2974. [CrossRef]

26. Fukuzumi, A.; Takehara, S.; Hase, K. Muscle activity analysis in vertical jump by direct dynamics simulation with musculo-skeletal model. Jpn. Soc. Mech. Eng. 2011, 77, 1686-1695. [CrossRef]

27. Yahya, U.; Arosha Senanayake SM, N.; Naim, A.G. A database-driven neural computing framework for classification of vertical jump patterns of healthy female netballers using 3D kinematics-EMG features. Neural Comput. Appl. 2020, 32, 1481-1500. [CrossRef]

28. Kollias, I.; Panoutsakopoulos, V.; Papaiakovou, G. Comparing jumping ability among athletes of various sports: Vertical drop jumping from $60 \mathrm{~cm}$. J. Strength Cond. Res. 2004, 18, 546-550. [PubMed]

29. Bishop, J.C.; Pangelinan, M. Motor skills intervention research of children with disabilities. Res. Dev. Disabil. 2018, 74, 14-30. [CrossRef] [PubMed] 